\section{Mini review: The potential of Mesenchymal Stem Cells in diabetes mellitus}

\author{
Narasimman Gurusamy*
}

CrossMark

\section{ABSTRACT}

While exogenous insulin and oral hypoglycemic agents are helpful in controlling the blood glucose level in diabetic patients, these agents are occasionally resulted in hypoglycemic coma. Considering the epidemiology of the diabetic population in the world, we require a better therapeutic strategy like expanding the existing beta- cells within the body or by supplying exogenous insulin-producing stem cells. A variety of stem cells have been tested for the treatment of type 1 and type 2 diabetes mellitus, and among them, mesenchymal

stem cells (MSCS) are widely used because of their immunomodulatory and low-immunogenic characteristics. So far, eight clinical trials have been completed using MSCs for the treatment of diabetes mellitus. Although the results of the currently available clinical trials are encouraging, i.e. in improving function of the pancreatic beta cells and in controlling the complications associated with diabetes, we require larger, randomized, and double-blinded studies, with a longer duration of follow-up, to validate the findings obtained.

Key Words: diabetes mellitus, mesenchymal stem cells, stem cells therapy

${ }^{*}$ Corresponding to: Dr. Narasimman Gurusamy, Assistant Professor, Department of Pharmacology, College of Pharmacy, King Khalid University, Abha - 61441, Kingdom of Saudi Arabia. Phone: +966564966522; Fax+966-72257832;

gurunaras@gmail.com or ngurusamy@kku.edu.sa

Cite This Article: Gurusamy, N. 2017. Mini review: The potential of Mesenchymal Stem Cells in diabetes mellitus. Diabesity 3(1): 1-4. Doi: 10.15562/diabesity.2017.37

\section{INTRODUCTION}

Diabetes mellitus is characterized by hyperglycemia and caused by the inadequate insulin secretion from pancreatic beta cells or by the insufficient utilization of the secreted insulin. According to the International Diabetes Federation, one in every 11 adults is having diabetes, resulted in 5 million deaths in 2015. Autoimmune-mediated destruction of pancreatic beta cells causes type 1 diabetes mellitus (T1DM), which is also known as juvenile-onset diabetes. Whereas, the type 2 diabetes mellitus (T2DM), also known as adult onset diabetes, commonly linked with obesity, and accounts for $>95 \%$ of diabetes cases worldwide, is associated with insulin resistance due to the improper utilization of glucose, and insulin deficiency due to the dysfunction of pancreatic beta cells.

Although exogenous insulin and oral hypoglycemic agents are helpful in decreasing the blood glucose level in diabetic patients, these agents can result in hypoglycemic coma, and they are not capable of mimicking endogenously secreted insulin, which provides a tight control over the blood glucose level. While the whole pancreas transplant or islet transplantation is an option to achieve post-operative insulin-independence, the mortality associated with the surgery, and the lifelong immunosuppression and the availability of donor tissue remains an issue. Considering these, a better therapeutic option would be to expand the existing beta- cells within the body or by supplying exogenous insulin-producing stem cells.
For the treatment of T1DM and T2DM, several sources of stem cells, such as, embryonic stem cells, induced pluripotent stem cells, bone marrow-derived hematopoietic stem cells, bone marrow-derived mesenchymal stem cells (MSCs), umbilical cord blood-derived MSCs, adipose tissue-derived MSCs, pancreas-derived multipotent precursor and progenitor cells etc. have been employed. ${ }^{1,2}$ However, MSCs are widely studied source of stem cells for the treatment of diabetes mellitus, mainly due to their immunomodulatory and low-immunogenic characteristics, and besides, they can be isolated from various tissues. ${ }^{3}$ The current review will focus on the therapeutic potential of MSCs in treating diabetes mellitus.

\section{MSCs for Diabetes Mellitus}

The main characteristics of MSCs are their ability for self-renewal, immunomodulation, and differentiation into tissues of mesodermal origin. Although, they can be found in many postnatal organs and tissues, they are frequently isolated from bone marrow, adipose tissue, and umbilical cord blood. MSCs show a variable expression levels of CD105, CD73, stromal antigen-1, CD44 and CD90 etc, but, lacking the hematopoietic cell markers such as CD14, CD45 and CD31 etc. ${ }^{4}$ Since the year 2005, the number of publications associated with MSCs for the treatment of diabetes have been increased constantly. The number of clinical trials associated with 'mesenchymal stem cells AND diabetes' 
according to the website ClinicalTrials.gov, is 47 , as of now, and of which, 8 studies have already been completed.

The prospective clinical study of Carlsson et $\mathrm{al}^{5}$ showed that the treatment with bone marrow-derived mesenchymal stromal cells in 20 adult patients with newly diagnosed type 1 diabetes was found to be safe, and preserved the $\beta$-cells function, measured via $C$-peptide concentrations in the blood, in response to a mixed-meal tolerance test at 1-year follow-up. Although this study results are encouraging, it necessitates a larger study with a longer duration of follow-up. In contrast to the study of Carlsson et al, who involved the newly diagnosed type 1 diabetic patients, the study of Cai et $\mathrm{al}^{6}$ involved established type 1 diabetic patients, and using umbilical cord-derived mesenchymal stromal cells along with autologous bone marrow mononuclear cells transplantation, importantly, without immunotherapy, showed only a moderate improvement in insulin secretion at 1-year follow-up. In type 2 diabetic patients, intravenous infusion of adult allogeneic bone marrow-derived mesenchymal precursor cells was found to be safe at 12 weeks, and a level of $<7 \% \mathrm{HbA} 1 \mathrm{c}$ was achieved in 8 out of 45 patients at 12 -weeks period.?

Zhao et $\mathrm{al}^{8}$ attempted an interesting therapy, where the T1DM patient's lymphocytes are separated from the whole blood and briefly co-cultured them with adherent human cord blood-derived multipotent stem cells, before sending them back to the patient's circulation. This 'educator' therapy reversed the autoimmunity, promoted the regeneration of islet $\beta$ cells and markedly improved C-peptide levels.

Lee et $\mathrm{al}^{9}$ have studied the effect of human bone marrow-derived MSCs (hMSCs) in experimental diabetes using NOD/scid mice. In which, intra-cardiac infusion of hMSCs reduced the blood glucose level in mice through an increase in pancreatic beta cells and islets, resulted in producing mouse insulin. In addition, there was an improvement in renal lesion through decreased mesangial thickening and macrophage infiltration in the kidneys.

Pancreatic duodenal homeobox 1 (Pdx1) plays a key role in the differentiation of various non- $\beta$-cells into insulin-producing cells, and Karnieli et al generated insulin-producing cells from human bone marrow mesenchymal stem cells through transduction of Pdx1 gene. ${ }^{10}$ In another study, human bone marrow-derived MSCs have been differentiated into insulin-producing cells through a differentiation protocol using high glucose, nicotinamide, and exendin-4. Importantly, these cells exhibited changes in the level of intracellular $\mathrm{Ca}^{2+}$ in response to glucose stimulation, as that seen in pancreatic $\beta$-cells in response to glucose-stimulated insulin secretion. Furthermore, transplantation of these in-vitro differentiated cells into streptozotocin-induced diabetic nude mice produced human insulin. ${ }^{11}$

Bassi et $\mathrm{al}^{12}$ injected the adipose-derived mesenchymal stem cells into an animal model of T1DM mice, and demonstrated a reversal of hyperglycemia in $78 \%$ of cases, in addition to an increase in the levels of circulating insulin, glucagon, and amylin, although a steady climb in glucose levels were found later. Further, the immunomodulatory effects of MSCs were explained by the reduction in the infiltration of inflammatory cells in pancreatic islets, and by an increase in CD4+ regulatory T-cells (Tregs), which are responsible for suppressing potentially deleterious $\mathrm{T}$ helper cells.

Kono et $\mathrm{al}^{13}$ have shown that the systemic administration of human adipose-derived stromal cells improved glucose tolerance, increased the proliferation of $\beta$-cells and preserved $\beta$-cells mass in streptozotocin-induced T1DM mice. In-vitro co-culturing of islets with human adipose-derived stromal cells upregulated TIMP-1, which can prevent cytokine-induced death of $\beta$-cells. Another interesting mechanism was shown by Gao et al, ${ }^{14}$ who cultured bone marrow derived mesenchymal stem cells, and this conditioned media alone promoted islet cell proliferation in-vitro through Akt and Erk dependent manner.

Mechanistically, transplanted MSCs can release soluble factors like cytokines, chemokines, interleukins and secondary messenger molecules etc., which can enhance the cell survival and improve the tissue repair mechanisms. The immunomodulatory functions of MSCs is mainly achieved through alteration of the secretion profile of dendritic cells, resulting in an increased production of anti-inflammatory cytokine interleukin-10 and a decreased production of interferon-gamma and interleukin-12. Furthermore, the proliferation of T-cells can be inhibited by MSCs through secretion of soluble factors like TGF- $\beta$ or interleukin-10. ${ }^{15}$ Kim et al have shown that human MSCs can interact with their mechanical microenvironment and trigger the intracellular calcium oscillation, which can further trigger the transcriptional regulation of the pro survival cellular factors. ${ }^{16,17}$

\section{MSCs for Diabetic Complications}

In addition to the improvement of pancreatic regeneration, MSCs have also been shown to improve the complications of diabetes, such as diabetic retinopathy, neuropathy, nephropathy and cardiomyopathy. ${ }^{18}$ Intravitreal injection of adipose tissue-derived stromal cells improved the electroretinogram and retinal histopathology through a decreased vascular 
leakage and the down-regulation of inflammatory genes in streptozotocin-induced diabetic athymic nude rats. This study demonstrated that the adipose-derived stromal cells can rescue the neural retina from hyperglycemia-induced degeneration, and improved visual function. ${ }^{19}$

Shibata et a $\mathrm{l}^{20}$ transplanted bone marrow-derived MSCs into hind limb skeletal muscles of streptozotocin-induced rats. Although transplanted MSCs were not incorporated into any new structures, the MSCs were found in the gaps between the muscle fibres, where the secretion of vascular endothelial growth factor and basic fibroblast growth factor was significantly increased. Furthermore, diabetes-induced hypoalgesia, delayed nerve conduction velocity, decreased sciatic nerve blood flow, and the abnormal sural nerve morphometry were normalized in MSCs' transplanted diabetic animals. Thus, the paracrine effects of transplanted MSCs ameliorated the diabetic neuropathy. Although the mechanism is not clear in the study of Ezquer et al, ${ }^{21}$ who demonstrated that the injection of MSCs into diabetic mice produced histologically normal glomeruli, preventing the diabetic nephropathy, in addition to showing the morphologically normal $\beta$-cell islets.

Zhang $\mathrm{N}$ et $\mathrm{al}^{22}$ demonstrated that the injection of MSCs through the femoral vein 8-weeks after streptozotocin injection, resulted in some trans-differentiation of MSCs into cardiac myocytes, and increased myocardial arteriolar density, decreased collagen volume, leading to an improved cardiac function in the diabetic myocardium. In the same study, it was also found that, MSCs can induce cardiomyogenesis and angiogenesis through the release of paracrine factors like vascular endothelial growth factor, insulin-like growth factor-1, adrenomedullin, and hepatocyte growth factor. In the randomized clinical trial of POSEIDON, transendocardial injection of MSCs in patients with chronic ischemic cardiomyopathy improved the cardiac remodeling and the ventricular functions by reducing the scar size. ${ }^{23}$

\section{CONCLUDING REMARKS}

From the pre-clinical and clinical studies, it is clear that treatment with MSCs improved the regeneration of pancreatic $\beta$-cells in T1DM through the release of paracrine factors and immunomodulatory function. Moreover, the results of several ongoing clinical trials are expected to have major impact on the treatment of diabetes mellitus. A recent meta-analysis study compared several clinical trials utilizing various stem cells for the treatment of diabetes mellitus. ${ }^{24}$ Although this meta-analysis showed that therapy with $\mathrm{CD} 34^{+}$hematopoietic stem cells showed a superior outcomes, this study has several serious limitations, such as including only a small number of trials, which in turn include only a low number of patients, and the follow-up period was not sufficiently long in order to build any significant conclusion. Finally, although the results of the currently available clinical trials involving MSCs in treating diabetes are encouraging, it is necessary to have larger, randomized, and double-blinded studies, with a longer duration of follow-up, in order to validate the findings obtained.

\section{REFERENCES}

1. Lilly MA, Davis MF, Fabie JE, Terhune EB, Gallicano GI. Current stem cell based therapies in diabetes. Am J Stem Cells. 2016 Oct 20;5(3):87-98. PubMed PMID: 27853630;

2. Chhabra P, Brayman KL. Stem cell therapy to cure type 1 diabetes: from hype to hope. Stem Cells Transl Med. 2013 May;2(5):328-36. doi: 10.5966/sctm.2012-0116. PMID: 23572052

3. Fiorina P, Voltarelli J, Zavazava N. Immunological applications of stem cells in type 1 diabetes. Endocr Rev. 2011 Dec;32(6):725-54. doi: 10.1210/er.2011-0008. PMID: 21862682

4. Volarevic V, Arsenijevic N, Lukic ML, Stojkovic M.Concise review: Mesenchymal stem cell treatment of the complications of diabetes mellitus. Stem Cells. 2011 Jan;29(1):5-10. doi: 10.1002/stem.556. PMID: 21280154

5. Carlsson PO, Schwarcz E, Korsgren O, Le Blanc K. Preserved $\beta$-cell function in type 1 diabetes by mesenchymal stromal cells. Diabetes. 2015 Feb;64(2):587-92. doi: 10.2337/db14-0656. PMID: 25204974

6. Cai J, Wu Z, Xu X, Liao L, Chen J, Huang L, Wu W, Luo F, Wu C, Pugliese A, Pileggi A, Ricordi C, Tan J. Umbilical Cord Mesenchymal Stromal Cell With Autologous Bone Marrow Cell Transplantation in Established Type 1 Diabetes: A Pilot Randomized Controlled Open-Label Clinical Study to Assess Safety and Impact on Insulin Secretion. Diabetes Care. 2016 Jan;39(1):149-57. doi: 10.2337/dc15-0171. PMID: 26628416

7. Skyler JS, Fonseca VA, Segal KR, RosenstockJ; MSB-DM003 Investigators..Allogeneic Mesenchymal Precursor Cells in Type 2 Diabetes: A Randomized, Placebo-Controlled, Dose-Escalation Safety and Tolerability Pilot Study. Diabetes Care. 2015 Sep;38(9):1742-9. doi: 10.2337/dc142830. PMID: 26153271

8. Zhao Y, Jiang Z, Zhao T, Ye M, Hu C, Yin Z, Li H, Zhang Y, Diao Y, Li Y, Chen Y, Sun X, Fisk MB, Skidgel R, Holterman M, Prabhakar B, Mazzone T. Reversal of type 1 diabetes via islet $\beta$ cell regeneration following immune modulation by cord blood-derived multipotent stem cells. BMC Med. 2012 Jan 10;10:3. doi: 10.1186/1741-7015-10-3. PMID: 22233865

9. Lee RH, Seo MJ, Reger RL, et al. Multipotent stromal cells from human marrow home to and promote repair of pancreatic islets and renal glomeruli in diabetic NOD/scid mice. Proc Natl Acad Sci U S A 2006;103:17438-17443 PMID:17088535

10. Karnieli O, Izhar-Prato Y, Bulvik S, Efrat S. Generation of insulin-producing cells from human bone marrow mesenchymal stem cells by genetic manipulation. Stem Cells. 2007;25(11):2837-44. Epub 2007/07/07.

11. Xin Y, Jiang X, Wang Y, Su X, Sun M, Zhang L, Tan Y, Wintergerst KA, Li Y, Li Y. Insulin-Producing Cells Differentiated from Human Bone Marrow Mesenchymal Stem Cells In Vitro Ameliorate StreptozotocinInduced Diabetic Hyperglycemia. PLoS One. 2016 Jan 12;11(1):e0145838. doi: 10.1371/journal.pone.0145838. PubMed PMID: 26756576; 
12. Bassi ÊJ, Moraes-Vieira PM, Moreira-Sá CS, Almeida DC, Vieira LM, Cunha CS, Hiyane MI, Basso AS, PachecoSilva A, Câmara NO. Immune regulatory properties of allogeneic adipose-derived mesenchymal stem cells in the treatment of experimental autoimmune diabetes. Diabetes. 2012 Oct;61(10):2534-45. PMID: 22688334

13. Kono TM, Sims EK, Moss DR, Yamamoto W, Ahn G, Diamond J, Tong X, Day KH, Territo PR, Hanenberg H, Traktuev DO, March KL, Evans-Molina C. Human adipose-derived stromal/stem cells protect against STZinduced hyperglycemia: analysis of hASC-derived paracrine effectors. Stem Cells. 2014 Jul;32(7):1831-42. doi: 10.1002/stem.1676. PMID: 24519994

14. Gao X, Song L, Shen K, Wang H, Qian M, Niu W, Qin X. Bone marrow mesenchymal stem cells promote the repair of islets from diabetic mice through paracrine actions. Mol Cell Endocrinol. 2014 May 5;388(1-2):41-50. doi: 10.1016/j.mce.2014.03.004. PMID: 24667703

15. Fiorina $\mathrm{P}$, Jurewicz $\mathrm{M}$, Augello A, et al. Immunomodulatory function of bone marrow-derived mesenchymal stem cells in experimental autoimmune type 1 diabetes. J Immunol 2009;183:993-1004 pmid:19561093

16. Kim TJ, Joo C, Seong J, Vafabakhsh R, Botvinick EL, Berns MW, et al. Distinct mechanisms regulating mechanical force-induced $\mathrm{Ca}(2)(+)$ signals at the plasma membrane and the ER in human MSCs. eLife. 2015;4:e04876. Epub 2015/02/11.

17. Kim TJ, Sun J, Lu S, Qi YX, Wang Y. Prolonged mechanical stretch initiates intracellular calcium oscillations in human mesenchymal stem cells. PLoS One. 2014 Oct 20;9(10):e109378. doi: 10.1371/journal.pone.0109378. PMID: 25329052

18. Khamaisi M, Balanson SE. Stem Cells for Diabetes Complications: A Future Potential Cure. Rambam Maimonides Med J. 2017 Jan 30;8(1). doi: 10.5041/ RMMJ.10283. PMID: 28178432

19. Rajashekhar G, Ramadan A, Abburi C, Callaghan B, Traktuev DO, Evans-Molina C, Maturi R, Harris A, Kern TS, March KL. Regenerative therapeutic potential of adipose stromal cells in early stage diabetic retinopathy. PLoS One. 2014 Jan 9;9(1):e84671. doi: 10.1371/journal. pone.0084671. PMID: 24416262

20. Shibata T, Naruse K, Kamiya H, Kozakae M, Kondo M, Yasuda Y, Nakamura N, Ota K, Tosaki T, Matsuki T, Nakashima E, Hamada Y, Oiso Y, Nakamura J. Transplantation of bone marrow-derived mesenchymal stem cells improves diabetic polyneuropathy in rats. Diabetes. 2008 Nov;57(11):3099-107. doi: 10.2337/db080031. PubMed PMID: 18728233

21. Ezquer FE, Ezquer ME, Parrau DB, Carpio D, Yañez AJ, Conget PA. Systemic administration of multipotent mesenchymal stromal cells reverts hyperglycemia and prevents nephropathy in type 1 diabetic mice. Biol Blood Marrow Transplant. 2008 Jun;14(6):631-40. doi: 10.1016/j. bbmt.2008.01.006. PMID: 18489988

22. Zhang N, Li J, Luo R, Jiang J, Wang JA. Bone marrow mesenchymal stem cells induce angiogenesis and attenuate the remodeling of diabetic cardiomyopathy. Exp Clin Endocrinol Diabetes. 2008 Feb;116(2):104-11. doi: 10.1055/s-2007-985154. PMID: 18286426

23. Suncion VY, Ghersin E, Fishman JE, Zambrano JP, Karantalis V, Mandel N, Nelson KH, Gerstenblith G, DiFede Velazquez DL, Breton E, Sitammagari K, Schulman IH,Taldone SN, Williams AR, Sanina C, Johnston PV, Brinker J, Altman P, Mushtaq M,Trachtenberg B, Mendizabal AM, Tracy M, Da Silva J, McNiece IK, Lardo AC, George RT, Hare JM, Heldman AW. Does transendocardial injection of mesenchymal stem cells improve myocardial function locally or globally?: An analysis from the Percutaneous Stem Cell Injection Delivery Effects on Neomyogenesis (POSEIDON) randomized trial. Circ Res. 2014 Apr 11;114(8):1292-301. doi:10.1161/ CIRCRESAHA.114.302854. PubMed PMID: 24449819;

24. El-Badawy A, El-Badri N. Clinical Efficacy of Stem Cell Therapy for Diabetes Mellitus: A Meta-Analysis. PLoS One. 2016 Apr 13;11(4):e0151938. doi: 10.1371/journal. pone.0151938. PMID: 27073927 